\title{
DETERMINAN PENGGUNAAN MEDIA SOSIAL, KREATIVITAS DAN PELATIHAN TERHADAP PENGEMBANGAN USAHA MIKRO KECIL DAN MENENGAH (UMKM) COFFEE SHOP DI KOTA BEKASI
}

\author{
Sri Yanthy Yosepha \\ sriy@unsurya.ac.id \\ Fakultas Ekonomi, Universitas Dirgantara Marsekal Suryadarma
}

\begin{abstract}
Abstrak
UMKM merupakan Usaha ekonomi produktif yang berdiri sendiri, yang dilakukan oleh orang perorangan atau badan usaha yang bukan merupakan anak perusahaan guna mendapatkan benefit. Pada saat pandemic ini UMKM Coffee Shop kota Bekasi harus berjuang mengembangkan produk agar tetap bertahan. Penelitian ini bertujuan untuk mengetahui pengaruh penggunaan media sosial dan kreativitas dan pelatihan terhadap pengembangan usaha mikro, kecil dan menengah Coffee Shop di kota Bekasi. Rumusan masalah penelitian ini yaitu : Adakah pengaruh variable Media social, kreativitas dan Pelatihan secara parsial dan simultan berpengaruh terhadap Pengembangan Usaha. Tujuan dan manfaat dari ini mengetahui pengaruh parsial dan simultan variable bebas terhadap variable independen. Penelitian ini menggunakan sampel yang terdiri dari 100 responden. Teknik analisis data menggunakan uji normalitas, regresi linier berganda, uji t, uji $\mathrm{F}$ dengan jenis penelitian kuantitatif dan sumber data yang digunakan adalah primer dan sekunder.

Hasil penelitian ini menunjukkan bahwa penggunaan media sosial secara parsial berpengaruh terhadap pengembangan usaha, kreativitas secara parsial berpengaruh terhadap pengembangan usaha, dan Pelatihan tidak berpengaruh pada pengembangan usaha serta penggunaan media sosial, kreativitas dan pelatihan secara simultan berpengaruh terhadap pengembangan usaha dengan nilai koefisien determinasinya sebesar $48,1 \%$ sedangkan sebesar 51,9\% dijelaskan oleh variabel lain yang tidak diteliti.
\end{abstract}

Kata kunci : Media Sosial, Kreativitas, Pengembangan Usaha, dan Pelatihan

\begin{abstract}
UMKMs are productive economic businesses that stand alone, which are carried out by individual or business entities that are not subsidiaries in order to get benefits. At the time of this pandemic, Bekasi City UMKMs had to struggle to develop products in order to survive. This study aims to determine the effect of using social media and creativity and training on the development of micro, small and medium-sized coffee shops in the city of Bekasi. The formulation of the problem in this research is: Is there any effect of variables on social media, creativity and training partially and simultaneously on business development. The purpose and benefit of this is knowing the partial and simultaneous effect of the independent variable on the independent variable. This study used a sample consisting of 100 respondents. The data analysis technique used normality test, multiple linear regression, $t$ test, $F$ test with quantitative research type and the data sources used were primary and secondary.
\end{abstract}


The results of this study indicate that the use of social media partially affects business development, creativity partially affects business development, but training has no effect on business development. The social media, creativity and training simultaneously affect business development with a coefficient of determination of $48,1 \%$ while $51.9 \%$ is explained by other variables not examined.

\section{Keywords: Social Media, Creativity, Business Development, and Training}

\section{PENDAHULUAN}

Usaha Mikro, Kecil dan Menengah (UMKM) adalah landasan dari perekonomian Indonesia yang dapat menambah tenaga kerja dan mengurangi pengangguran di tengah persaingan dalam mencari pekerjaan. Akhir tahun 2019 terjadi fenomena COVID-19 yang merupakan virus penyakit infeksi saluran pernafasan yang memiliki dampak bagi 188 negara yang terkonfirmasi, terutama negara Indonesia karena COVID-19 sangat berpengaruh bagi pertumbuhan ekonomi di Negara Indonesia terutama pada sektor perekonomian (Hanoatubun, 2020:147). Menurut Deputi Restrukturisasi Usaha Kementrian dan Usaha Kecil Menengah (Kemkop UKM) Eddy Satriya menyampaikan, sebanyak 2.322 koperasi dan 185.184 pelaku usaha UMKM terdampak pandemi COVID-19. Lebih banyak koperasi yang terkena dampak COVID19 bergerak pada bidang kebutuhan sehari-hari, sedangkan sektor UMKM yang paling terdampak bergerak di bidang makanan dan minuman (sumber : www.Depkop.go.id, 2020).

Selama pandemi COVID-19 ini sektor UMKM paling terdampak sehingga banyak dari pengusaha tersebut harus gulung tikar, karena permintaan jatuh dan sekitar 30 persen usaha yang terganggu (sumber: Bps.go.id, 2020). Dilihat dari permasalahan UMKM yang terjadi, maka diperlukan upaya untuk mempertahankan UMKM dan pengembangan UMKM terutama pengembangan pada produk yang akan diproduksi dan diperjualbelikan .

Di saat pandemi COVID-19 banyak pelaku UMKM yang mengalami kendala, salah satu UMKM yang masih bertahan dan berkembang adalah usaha di bidang kuliner khusus minuman, seperti minuman kopi. Menurut International Coffee Organizatition tahun 2020, produksi kopi di dunia pada tahun 2019/2020 mengalami penurunan sebesar 1,6 persen menjadi 168,55 juta karung akibat penurunan produksi arabika sebesar 5,1 persen, sedangkan produksi robusta naik 3,2 persen. Produksi dari Asia dan 
Oseania tumbuh sebesar 4,1 persen. Produksi kopi di dunia melebihi konsumsi global sebesar 961.000 kantong seiring dengan penurunan kopi dunia sebesar 0,9 persen menjadi 167,59 juta kantong, sumber : (www.ico.org, 2020) . Data di atas menunjukan bahwa kopi banyak di minati di berbagai negara terutama di negara Indonesia.

Indonesia merupakan salah satu negara dengan produsen dan konsumsen kopi terbesar di dunia, usaha ini sangat menjanjikan terutama di zaman modern untuk membuka UMKM Coffee Shop agar konsumen tertarik baik dengan minuman coffee dan suasana kedai . Menurut Ario Fajar Head of Marketing PT Toffin Indonesia, jumlah kedai kopi di Indonesia dalam tiga tahun terakhir meningkat tiga kali lipat dari 1.083 outlet di 2016 menjadi 3.000 outlet pada akhir 2019, dan di proyeksi terus berkembang pada tahun 2020 kedai kopi akan tumbuh 10 persen hingga 15 persen sekitar 3.300 sampai 3.450 kedai kopi, sumber : (BrewFest, 2020).

UMKM Coffee Shop merupakan usaha dalam bidang kuliner khusus menjual minuman terbukti bahwa di zaman modern sekarang banyak diminati. Keahlian barista yang meracik minuman di Coffee Shop menjadi minuman yang enak, komposisi yang pas, keunikan produk, tempat yang nyaman disajikan oleh pemilik UMKM Coffee Shop kepada konsumen. Dalam penelitian ini objek penelitian adalah UMKM yang menjalankan usaha kecil dalam bidang kuliner khusus minuman yaitu Coffee Shop di Kota Bekasi mengalami perkembangan yang cukup pesat, hampir \pm ada sekitar 100 usaha Coffee Shop dengan Segmen pasar coffee shop modern sebagian besar adalah anak milenial dimana strategi pemasaran menggunakan media sosial.

Dapat dilihat dari data Kementrian dan Usaha Kecil dan Menengah bahwa dengan jumlah data baru 8 juta UMKM atau $13 \%$ terhubung dengan market online dari jumlah UMKM di Indonesia (sumber: www.Depkop.go.id, 2020). Diartikan bahwa belum seluruh UMKM di Indonesia menggunakan dan terhubung dengan market online sehingga UMKM belum mampu memaksimalkan internet market online di era globalisasi. Salah satu bagian dari internet yang sedang berkembang adalah media sosial yang sangat berpotensi untuk mengembangkan UMKM dalam memasarkan produk sehingga penggunaan media sosial. Hal ini dikuatkan oleh penelitian Purwidiantoro et al (2016:31), bahwa media sosial adalah sekelompok aplikasi berbasiskan internet yang dibangun berdasarkan kerangka pikiran ideologi dan teknologi dari Web 2.0, dan memungkinkan terbentuknya kreasi pertukaran isi informasi dari pengguna internet. 
Seperti media sosial yang berkembang saat ini adalah : twitter, facebook, myspace, youtube, instagram, whatsapp, line, dan lain-lain.

Diinformasikan dari sumber Badan Pusat Statistik bahwa pada pandemi saat ini UMKM yang memang terganggu akibat dampak COVID-19, baru sekitar 50 sampai 70 persen UMKM menciptakan inovasi kreatif, sumber: Bps.go.id (2020). UMKM yang berada di Bekasi juga terganggu akibat COVID-19. Di artikan bahwa belum 100\% seluruh UMKM itu menciptakan sebuah inovasi dan kreatif pada usaha. Karena kreativitas penting terutama pada produk agar menjadi ciri khas tersendiri, dan UMKM menggunakan modal yang kecil maka pemilik usaha harus kreatif agar berbeda. Sehingga walaupun harga produk UMKM tersebut mahal konsumen akan tertarik. Serta Pelatihan yang telah dilakukan akan meningkatkan kreativitas umkm dalam meningkatkan penjualan.

\section{LANDASAN TEORI DAN PENGEMBANGAN HIPOTESIS}

\section{Pengertian UMKM}

David Wijaya (2018:8), UMKM adalah kelompok usaha dengan jumlah terbesar dan terbukti handal menghadapi goncangan krisis ekonomi. Oleh karena itu pemerintah memberikan perhatian lebih terhadap UMKM karena bisa dikatakan bahwa UMKM adalah tumpuan terbesar rakyat Indonesia.

\section{Pengertian Pengembangan Usaha}

Arniti (2019:1756), pengembangan usaha adalah tanggung jawab dari setiap pengusaha atau wirausaha yang membutuhkan pandangan ke depan, motivasi dan kreativitas.

\section{Pengertian Media Sosial}

Nasrullah (2017:11), media sosial adalah medium di internet yang memungkinkan pengguna merepresentasikan dirinya maupun berinteraksi, bekerja sama, berbagi, berkomunikasi dengan pengguna lain, dan membentuk ikatan sosial secara virtual.

\section{Pengertian Kreativitas}

Dharmawati (2019:50), kreativitas adalah inisiatif terhadap penciptaan suatu produk atau proses yang bermanfaat, benar, tepat, dan bernilai. 


\section{Pengertian Pelatihan}

Sikula dalam Mangkunegara (2012: 50) mengatakan "Pelatihan adalah proses pendidikan jangka pendek yang mempergunakan prosedur sistimatis dan terorganisir dimana pegawai non managerial mempelajari pengetahuan dan keterampilan teknis dalam tujuan terbatas"

\section{KERANGKA BERPIKIR}

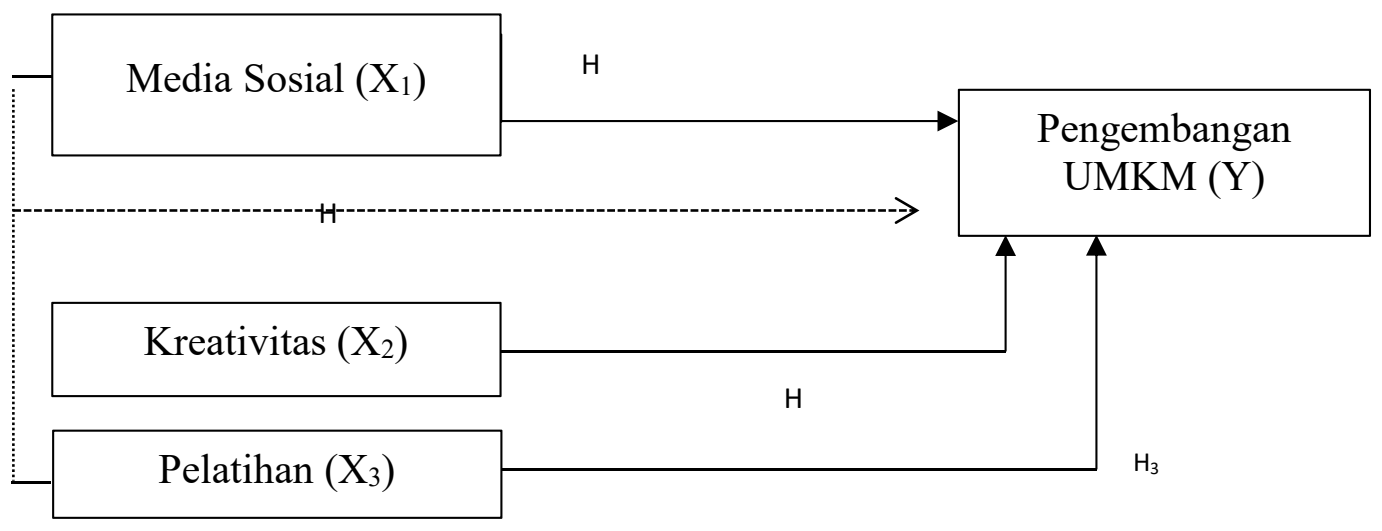

Gambar 1. Kerangka Berpikir

Keterangan:

$\mathrm{H}_{1}$ : Pengaruh parsial Media Sosial terhadap Pengembangan UMKM.

$\mathrm{H}_{2}$ : Pengaruh parsial Kreativitas terhadap Pengembangan UMKM.

$\mathrm{H}_{3}$ : Pengaruh parsial Pelatihan terhadap Pengembangan UMKM

$\mathrm{H}_{4}$ : Pengaruh simultan Media Sosial, Kreativitas dan Pelatihan terhadap Pengembangan UMKM

\section{METODE PENELITIAN}

Penelitian ini dilaksanakan di Kota Bekasi dengan objek Usaha Mikro Kecil dan Menengah (UMKM) bidang makanan dan minuman khusus Coffee Shop. populasi yang digunakan adalah Usaha Mikro, Kecil dan Menengah (UMKM) di wilayah Kota Bekasi dengan 100 sampel. Jenis penelitian ini adalah data kuantitatif. Sumber data yang digunakan dalam penelitian ini adalah Data Primer dan Sekunder. 


\section{HASIL DAN PEMBAHASAN}

\section{Uji Normalitas}

Menurut Widodo (2019:111), uji normalitas bertujuan untuk mengetahui distribusi residual. Pengujian normalitas menggunakan uji normal Kolmogorov- Smirnov (K-S).

a. Jika nilai signifikan $>0,05$ data berdistribusi normal

b. Jika nilai sginifikan $<0,05$ data tidak berdistribusi normal

Tabel 1. Hasil Uji Normalitas

\begin{tabular}{|c|c|c|}
\hline \multicolumn{3}{|c|}{\begin{tabular}{|l|} 
One-Sample Kolmogorov-Smirnov Test \\
\end{tabular}} \\
\hline & & $\begin{array}{l}\text { Unstandardized } \\
\text { Residual }\end{array}$ \\
\hline \multicolumn{2}{|l|}{$\mathrm{N}$} & 100 \\
\hline \multirow[t]{2}{*}{ Normal Parameters ${ }^{\mathrm{a}, \mathrm{b}}$} & Mean & .0000000 \\
\hline & \begin{tabular}{|l|} 
Std. Deviation \\
\end{tabular} & 5.30614579 \\
\hline \multirow[t]{3}{*}{ Most Extreme Differences } & Absolute & .051 \\
\hline & \begin{tabular}{|l|} 
Positive \\
\end{tabular} & .033 \\
\hline & Negative & -.051 \\
\hline \multicolumn{2}{|l|}{ Test Statistic } & .051 \\
\hline \multicolumn{2}{|l|}{ Asymp. Sig. (2-tailed) } & $.200^{\mathrm{c}, \mathrm{d}}$ \\
\hline \multicolumn{3}{|l|}{ a. Test distribution is Normal. } \\
\hline \multicolumn{3}{|l|}{ b. Calculated from data. } \\
\hline \multicolumn{3}{|c|}{ c. Lilliefors Significance Correction. } \\
\hline \multicolumn{3}{|c|}{ d. This is a lower bound of the true significance. } \\
\hline
\end{tabular}

Berdasarkan tabel di atas hasil uji normalitas dengan Kolmogorov Smirnov diperoleh nilai Asymp. Sig. 0,200 >0,05, sehingga dapat disimpulkan bahwa data sampel dari populasi yang diuji dinyatakan berdistribusi normal.

\section{Uji Multikolinearitas}

Menurut Imam Ghozali (2013:135), untuk menguji apakah model regresi ditemukan adanya korelasi antar variabel bebas (independen), model regresi yang baik seharusnya tidak terjadi korelasi di antara variabel independen. Pedoman suatu model regresi yang bebas multikolinearitas adalah mempunyai angka tolerance mendekati 1. Batas VIF adalah 10 , maka artinya :

a. Jika tolerance $<0,1$ dan atau VIF $>10$, maka terjadi multikolinearitas

b. Jika tolerance $>0,1$ dan atau $\mathrm{VIF}<10$, maka tidak terjadi multikolinearitas 
Tabel 2. Hasil Uji Multikolinearitas

\begin{tabular}{|c|c|c|c|c|c|c|c|c|}
\hline & \multirow[b]{2}{*}{ Model } & \multicolumn{2}{|c|}{$\begin{array}{c}\text { Unstandardized } \\
\text { Coefficients }\end{array}$} & \multirow{2}{*}{$\begin{array}{c}\text { Standardized } \\
\text { Coefficients } \\
\text { Beta } \\
\end{array}$} & \multirow[b]{2}{*}{$\mathrm{T}$} & \multirow[b]{2}{*}{ Sig. } & \multicolumn{2}{|c|}{$\begin{array}{l}\text { Collinearity } \\
\text { Statistics }\end{array}$} \\
\hline & & B & Std. Error & & & & $\begin{array}{c}\text { Toleranc } \\
\mathrm{e}\end{array}$ & VIF \\
\hline \multirow[t]{4}{*}{1} & (Constant) & 30.773 & 7.249 & & 4.245 & .000 & & \\
\hline & $\begin{array}{l}\text { MEDIA } \\
\text { SOSIAL }\end{array}$ & .099 & .120 & .106 & .828 & .410 & .329 & 3.036 \\
\hline & $\begin{array}{l}\text { KREATIVIT } \\
\text { AS }\end{array}$ & .681 & .127 & .539 & 5.360 & .000 & .535 & 1.871 \\
\hline & PELATIHAN & .124 & .087 & .146 & 1.419 & .159 & .513 & 1.949 \\
\hline
\end{tabular}

Dari hasil pengolahan data diatas, diketahui bahwa Nilai Tolerance variabel Penggunaan Media Sosial $\left(\mathrm{X}_{1}\right)$, sebesar 0,329, variabel Kreativitas $\left(\mathrm{X}_{2}\right)$ sebesar 0,535, variabel Pelatihan $\left(\mathrm{X}_{3}\right)$ sebesar $0513,>0,10$.

Sementara itu, nilai VIF variabel Penggunaan Media Sosial $\left(\mathrm{X}_{1}\right)$ sebesar 3,036, variabel Keativitas $\left(\mathrm{X}_{2}\right)$ yakni sebesar 1,871, variabel Pelatihan sebesar 1,949<10,00.

Dengan demikian, maka variabel Penggunaan Media Sosial $\left(\mathrm{X}_{1}\right)$, variabel Kreativitas dan variabel Pelatiahan $\left(\mathrm{X}_{3}\right)$ tidak terjadi Multikolinearitas.

\section{Analisis Regresi Linear Berganda}

Analisis regresi linier berganda dapat digunakan untuk mengetahui bagaimana pengaruh variabel bebas yaitu Penggunaan Media Sosial $\left(\mathrm{X}_{1}\right)$, kreativitas $\left(\mathrm{X}_{2}\right)$ dan Pelatihan $\left(\mathrm{X}_{3}\right)$ terhadap Pengembangan Usaha (Y) pada UMKM Coffee Shop di Kota Bekasi. Persamaan regresi linier berganda yang digunakan dalam penelitian ini adalah sebagai berikut:

Tabel 3. Hasil Analisis Regresi Linear Berganda

\begin{tabular}{|c|c|c|c|c|c|c|}
\hline \multicolumn{7}{|c|}{ Coefficients $^{\mathrm{a}}$} \\
\hline & \multirow[b]{2}{*}{ Model } & \multicolumn{2}{|c|}{ Unstandardized Coefficients } & \multirow{2}{*}{$\begin{array}{c}\begin{array}{c}\text { Standardized } \\
\text { Coefficients }\end{array} \\
\text { Beta } \\
\end{array}$} & \multirow[b]{2}{*}{$\mathrm{T}$} & \multirow[b]{2}{*}{ Sig. } \\
\hline & & B & Std. Error & & & \\
\hline \multirow[t]{4}{*}{1} & (Constant) & 34.000 & 6.919 & & 4.914 & .000 \\
\hline & Media Sosial & .206 & .094 & .221 & 2.207 & .030 \\
\hline & Kreativitas & .655 & .126 & .518 & 5.181 & .000 \\
\hline & Pelatihan & .124 & .087 & .146 & 1.419 & .159 \\
\hline
\end{tabular}




$$
\begin{gathered}
Y=a+b 1 X 1+b 2 X 2+b 3 X_{3} \\
Y=34,000+0,206 X_{1}+0,655 X_{2}+0,124 X_{3}
\end{gathered}
$$

Keterangan :

$\begin{array}{ll}\mathrm{Y} & : \text { Pengembangan Usaha } \\ \mathrm{a} & : \text { Konstanta } \\ \mathrm{b}_{1} \mathrm{~b}_{2} \mathrm{~b}_{3} & : \text { Koefisien regresi ( nilai peningkatan ataupun penurunan) } \\ \mathrm{X}_{1} & : \text { Penggunaan Media Sosial } \\ \mathrm{X}_{2} & : \text { Kreativitas } \\ \mathrm{X}_{3} & : \text { Pelatihan }\end{array}$

Berdasarkan persamaan regresi tersebut menunjukkan dapat dijelaskan sebagai berikut:

a. Nilai konstanta (a) bernilai positif sebesar 34,000 artinya apabila variabel penggunaan media sosial dan kreativitas konstan atau sama dengan 0, maka pengembangan usaha sebesar 34,000.

b. Nilai koefisien $b_{1}$ bernilai positif sebesar 0,206 , artinya variabel penggunaan media sosial memiliki hubungan positif dan searah dengan pengembangan usaha. Kenaikan penggunaan media sosial sebesar satu satuan, akan meningkatkan pengembangan usaha sebesar 0,206 satuan dan sebaliknya, dengan asumsi variabel lain konstan.

c. Nilai koefisien $b_{2}$ bernilai positif sebesar 0,655 , artinya variabel kreativitas memiliki hubungan positif dan searah dengan pengembangan usaha. Hal ini menunjukkan bahwa setiap kenaikan kreativitas sebesar satu satuan, akan meningkatkan pengembangan usaha sebesar 0,655 satuan dan sebaliknya dengan asumsi variabel lain konstan.

d. Nilai koefisien $b_{3}$ bernilai positif sebesar 0,124, artinya variabel Pelatihan memiliki hubungan positif dan searah dengan pengembangan usaha. Hal ini menunjukkan bahwa setiap kenaikan Pelatihan sebesar satu satuan, akan meningkatkan pengembangan usaha sebesar 0,124 satuan dan sebaliknya dengan asumsi variabel lain konstan.

\section{Uji Hipotesis Parsial (Uji t)}

Uji Parsial (Uji t) digunakan untuk mengetahui variasi hubungan antara variabel independen dan variabel dependen, apakah variabel independen benar-benar berpengaruh secara parsial terhadap variabel dependen. 
Tabel 4. Hasil Ui t Hipotesis Parsial

\begin{tabular}{|c|c|c|c|c|c|c|c|c|}
\hline \multicolumn{9}{|c|}{ Coefficients $^{\mathbf{a}}$} \\
\hline & \multirow[b]{2}{*}{ Model } & \multicolumn{2}{|c|}{$\begin{array}{c}\text { Unstandardized } \\
\text { Coefficients }\end{array}$} & \multirow{2}{*}{$\begin{array}{c}\text { Standardized } \\
\text { Coefficients } \\
\text { Beta } \\
\end{array}$} & \multirow[b]{2}{*}{$\mathrm{t}$} & \multirow[b]{2}{*}{ Sig. } & \multicolumn{2}{|c|}{ Collinearity Statistics } \\
\hline & & $\mathrm{B}$ & Std. Error & & & & Tolerance & VIF \\
\hline \multirow[t]{4}{*}{1} & (Constant) & 34.000 & 6.919 & & 4.914 & .000 & & \\
\hline & Media Sosial & .206 & .094 & .221 & 2.207 & .030 & .546 & 1.830 \\
\hline & Kreativitas & .655 & .126 & .518 & 5.181 & .000 & .546 & 1.830 \\
\hline & Pelatihan & .124 & .087 & .146 & 1.419 & .159 & .513 & 1.949 \\
\hline
\end{tabular}

\section{a. Pengujian Hipotesis 1}

Nilai thitung sebesar 2,207 $>\mathrm{t}_{\text {tabel }}$ sebesar 1,984 dan nilai signifikansi sebesar 0,030 $<0,05$, maka dapat disimpulkan $\mathrm{H}_{\mathrm{o}}$ ditolak dan $\mathrm{H}_{\mathrm{a}}$ diterima, menjawab hipotesis ke-1 artinya "Penggunaan media sosial berpengaruh terhadap pengembangan usaha pada usaha coffee shop di tiga Kecamatan yaitu Rawalumbu, Mustikajaya, dan Bekasi Selatan”.

\section{b. Pengujian Hipotesis 2}

Nilai $t_{\text {hitung }}$ sebesar 5,181 $>t_{\text {tabel }}$ sebesar 1,984 dan nilai signifikansi sebesar $0,000<0,05$, maka dapat disimpulkan $\mathrm{H}_{0}$ ditolak dan $\mathrm{H}_{\mathrm{a}}$ diterima, menjawab hipotesis ke-2 artinya "Kreativitas berpengaruh terhadap pengembangan usaha pada usaha coffee shop di Kota Bekasi

\section{c. Pengujian Hipotesis 3}

Nilai thitung sebesar $1.419<$ tabel sebesar 1,984 dan nilai signifikansi sebesar $0,159>0,05$ artinya dapat disimpulkan $\mathrm{H}_{0}$ diterima dan $\mathrm{H}_{\mathrm{a}}$ ditolak, menjawab hipotesis ke-3 artinya "Pelatihan tidak berpengaruh terhadap Pengembangan usaha pada usaha coffee shop di Kota Bekasi.

\section{Uji Hipotesis Simultan (Uji F)}

Uji F adalah pengujian terhadap koefisien regresi secara simultan. Pengujian ini dilakukan untuk mengetahui pengaruh semua variabel Independen (Penggunaan Media Sosial dan Kreativitas dan Pelatihan) yang terdapat di dalam model secara bersamasama (simultan) terhadap variabel Dependen (Pengembangan Usaha). $\mathrm{H}_{0}$ diterima jika nilai $F_{\text {hitung }}<\mathrm{F}_{\text {tabel }}$ dan $\mathrm{H}_{0}$ ditolak jika nilai $\mathrm{F}_{\text {hitung }}>\mathrm{F}_{\text {tabel }}=$ df $3(100-3=97) \mathrm{n}-\mathrm{k}-1, \alpha=$ $0,05)=3,09$. 
Tabel 5.Hasil Uji F Hipotesis Simultan

\begin{tabular}{|c|c|c|c|c|c|c|}
\hline \multicolumn{7}{|c|}{ ANOVA $^{\mathrm{a}}$} \\
\hline & Model & Sum of Squares & $\mathrm{Df}$ & Mean Square & $\mathrm{F}$ & Sig. \\
\hline \multirow[t]{3}{*}{1} & Regression & 2588.277 & 3 & \multirow{3}{*}{$\begin{array}{r}862.759 \\
29.035\end{array}$} & \multirow[t]{3}{*}{29.714} & \multirow[t]{3}{*}{$.000^{\mathrm{b}}$} \\
\hline & Residual & 2787.363 & 96 & & & \\
\hline & Total & 5375.640 & 99 & & & \\
\hline
\end{tabular}

a. Dependent Variable: PENGEMBANGAN

b. Predictors: (Constant), PELATIHAN, KREATIVITAS, MEDIA SOSIAL

Sumber: data penelitian diolah (2021)

Dari hasil pengolahan data di atas terlihat pengujian variabel independen secara bersama-sama terhadap variabel dependen dengan uji $\mathrm{F}$ hasil pengolahan data di atas menunjukkan nilai $F_{\text {hitung }}=29,035>F_{\text {tabel }}=3,09$, dan nilai signifikansi $0,000<0,05$, yang berarti bahwa hipotesis dalam penelitian ini $\mathrm{H}_{0}$ ditolak dan $\mathrm{H}_{\mathrm{a}}$ diterima. Menjawab hipotesis ke-4, artinya "Penggunaan Media Sosial, Kreativitas dan Pelatihan terdapat pengaruh yang positif dan signifikan secara simultan terhadap Pengembangan Usaha pada usaha coffee shop di Kota Bekasi”.

\section{Koefisien Determinasi Parsial}

Koefisien determinasi parsial digunakan untuk menentukan besarnya pengaruh dari salah satu variabel independen $(\mathrm{X})$ terhadap variabel dependen $(\mathrm{Y})$ secara parsial.

Tabel 6. Besaran Koefisien Determinasi Parsial

\begin{tabular}{|l|r|r|}
\hline \multicolumn{1}{|c|}{ Variabel } & Sumbangan Relatif & Dalam $\%$ \\
\hline Media Sosial (X1) & 0.12 & $12 \%$ \\
\hline Kreativitas (X2) & 0.74 & $74 \%$ \\
\hline Pelatihan (X3) & 0.12 & $12 \%$ \\
\hline
\end{tabular}

Berdasarkan tabel di atas bahwa besaran koefisien determinasi parsial untuk sumbangan relatif variable Media Sosial sebesar 12\%, kreativitas sebesar 74\% dan Pelatihan sebesar $12 \%$. Dengan demikian sumbangan relatif terbesar adalah kreativitas terhadap pengembangan usaha.

\section{Koefisien Determinasi $\left(\mathbf{R}^{2}\right)$}

Untuk mengetahui seberapa besar kontribusi variabel Pengembangan Usaha $\left(\mathrm{X}_{1}\right)$, Kreativitas $\left(\mathrm{X}_{2}\right)$ dan Pelatihan $\left(\mathrm{X}_{3}\right)$ terhadap variabel Pengembangan Usaha $(\mathrm{Y})$. Nilai koefisien determinasi disajikan pada tabel berikut ini. 
Tabel 7. Nilai Koefisien Determinasi $\mathrm{X}_{1}, \mathrm{X}_{2}, \mathrm{X}_{3}$ Terhadap $\mathrm{Y}$ Model Summary

\begin{tabular}{|r|r|r|r|r|r|}
\hline Model & \multicolumn{1}{|c|}{ R } & R Square & Adjusted R Square & $\begin{array}{c}\text { Std. Error of the } \\
\text { Estimate }\end{array}$ & Durbin-Watson \\
\hline 1 & .694 & .481 & .465 & 5.388 & 1.617 \\
\hline
\end{tabular}

a Predictors: (Constant), PELATIHAN, KREATIVITAS, MEDIA SOSIAL

Sumber: data penelitian diolah (2021)

Berdasarkan hasil pengolahan data di atas, maka dapat diketahui nilai R Square sebesar 0,481 hal ini menunjukkan bahwa variasi data variabel bebas yaitu Penggunaan Media Sosial $\left(\mathrm{X}_{1}\right)$, Kreativitas $\left(\mathrm{X}_{2}\right)$ dan Pelatihan $\left(\mathrm{X}_{3}\right)$ mampu menjelaskan variasi data dari variabel terikat yaitu Pengembangan Usaha (Y) sebesar 48,1\% sedangkan sebesar $51,9 \%$ dijelaskan oleh variabel lain yang tidak diteliti.

\section{HASIL PENELITIAN DAN PEMBAHASAN}

\section{Pengaruh Penggunaan Media Sosial $\left(\mathrm{X}_{1}\right)$ Terhadap Pengembangan Usaha (Y)}

Dalam Uji Regresi Linier Berganda terdapat persamaan regresi $\mathrm{Y}=34,000+$ $0,206 X_{1}+0,655 X_{2}=0,124 X_{3}$ yang artinya koefisien regresi variabel Penggunaan Media Sosial $\left(\mathrm{X}_{1}\right)$ sebesar 0,206. Dalam Uji Parsial (Uji t) variabel Penggunaan Media Sosial $\left(\mathrm{X}_{1}\right)$ menunjukkan bahwa nilai $t_{\text {hitung }}$ sebesar 2,207 $>t_{\text {tabel }}$ sebesar 1,984 dan nilai signifikansi sebesar $0,030<0,05$, maka dapat disimpulkan $\mathrm{H}_{\mathrm{o}}$ ditolak dan $\mathrm{H}_{\mathrm{a}}$ diterima.

Dengan demikian dapat disimpulkan bahwa hipotesis $\mathrm{H}_{\mathrm{a} 1}$ artinya dapat diterima “Penggunaan Media Sosial $\left(\mathrm{X}_{1}\right)$ berpengaruh positif terhadap Pengembangan Usaha (Y)" artinya $\mathbf{H}_{\mathbf{a} 1}$ dapat di terima. Hal ini diperkuat dengan juga dengan penelitian yang dilakukan oleh Moch Hari Purwidiantoro, Dany Fajar Kristanto, dan Widiyanto Hadi dengan judul Pengaruh Penggunaan Media Sosial terhadap Pengembangan Usaha Kecil Menengah (UKM) (2016) Vol. 1 No. 1 Maret 201631 ISSN: 2503-3565 e-ISSN: 2503-3689. Menyimpulkan bahwa UKM yang di observasi telah menggunakan media sosial dalam perusahaannya. Media sosial yang paling banyak digunakan adalah Facebook, Twitter dan Instagram. Bagi sebagian besar UKM manfaat penggunaan media sosial adalah untuk komunikasi personal dengan konsumen, Pemasaran dan iklan, mendata kebutuhan konsumen, memberikan respon pada konsumen, membantu pengambilan keputusan dan sebagai forum diskusi dengan konsumen. 


\section{Pengaruh Kreativitas $\left(\mathrm{X}_{2}\right)$ Terhadap Pengembangan Usaha (Y)}

Dalam Uji Regresi Linier Berganda terdapat persamaan regresi $\mathrm{Y}=34,000+$ $0,206 \mathrm{X}_{1}+0,655 \mathrm{X}_{2}+0,124 \mathrm{X}_{3}$ yang artinya koefisien regresi variabel Kreativitas $\left(\mathrm{X}_{2}\right)$ sebesar 0,655. Dalam Uji Parsial (Uji t) variabel Kreativitas $\left(\mathrm{X}_{2}\right)$ menunjukkan bahwa

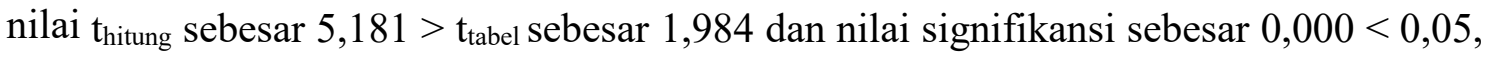
maka dapat disimpulkan $\mathrm{H}_{\mathrm{o}}$ ditolak dan $\mathrm{H}_{\mathrm{a}}$ diterima.

Dengan demikian dapat disimpulkan bahwa hipotesis $\mathrm{H}_{\mathrm{a} 2}$ dapat diterima “Kreativitas $\left(\mathrm{X}_{2}\right)$ berpengaruh terhadap Pengembangan Usaha (Y)" di terima. Hal ini diperkuat dengan juga dengan penelitian yang dilakukan oleh Dedi Purwana, Siti Juhaeriah dan I Ketut R. Sudiarditha dengan judul Pengaruh Karakteristik Kewirausahaan, Kreativitas dan Inovasi terhadap Perkembangan Usaha Pedagang di Pasar Seni Guwang Sukawati dan Vol. 14 No. 1 Agustus 2019 menunjukkan bahwa penggunaan kreativitas memiliki pengaruh terhadap pengembangan usaha. Berdasarkan hasil perhitungan untuk variabel Kreativitas di peroleh t-hitung sebesar $6.360>$ ttabel1.671 dengan tingkat signifikansi 0,000. Ini berarti Kreativitas secara parsial memiliki pengaruh positif dan signifikan terhadap Perkembangan Usaha Pedagang Di Pasar Seni Guwang Sukawat.

\section{Pengaruh Pelatihan $\left(X_{3}\right)$ Terhadap Pengembangan Usaha (Y)}

Dalam Uji Regresi Linier Berganda terdapat persamaan regresi $\mathrm{Y}=34,000+$ $0,206 \mathrm{X}_{1}+0,655 \mathrm{X}_{2}+0,124 \mathrm{X}_{3}$ yang artinya koefisien regresi variabel Pelatihan $\left(\mathrm{X}_{3}\right)$ sebesar 0,124. Dalam Uji Parsial (Uji t) variabel Pelatihan $\left(\mathrm{X}_{3}\right)$ menunjukkan bahwa

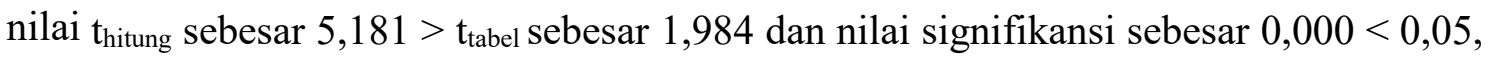
maka dapat disimpulkan $\mathrm{H}_{\mathrm{o}}$ diterima dan $\mathrm{H}_{\mathrm{a}}$ ditolak.

Dengan demikian dapat disimpulkan bahwa hipotesis $\mathrm{H}_{\mathrm{a} 3}$ dapat diterima "Pelatihan $\left(\mathbf{X}_{3}\right)$ tidak berpengaruh terhadap Pengembangan Usaha (Y)". Hal ini bertolak belakang dengan penelitian yang dilakukan oleh Bambang Susilo, Hendra Wijaya dan Nanik Yuliati dengan judul Pengaruh Pelatihan Terhadap Pengembangan Usaha di Koperasi Unit Desa (KUD) Marem Desa Serut Kecamatan Panti Kabupaten Jember Tahun 2013, yang merupakan hasil penelitian mahasiswa tahun 2014. Berdasarkan hasil perhitungan untuk variabel Pelatihan di peroleh t-hitung sebesar 0,92 > ttabel 0,45 dengan tingkat signifikansi 0,000. Ini berarti Pelatihan 
secara parsial memilki pengaruh terhadap Perkembangan Usaha Pedagang di Koperasi Unit Desa (KUD) Marem Desa Serut Kecamatan Panti Kabupaten Jember tahun 2014.

\section{Pengaruh Penggunaan Media Sosial $\left(X_{1}\right)$, Kreativitas $\left(X_{2}\right)$ dan Pelatihan $\left(X_{3}\right)$ Terhadap Pengembangan Usaha (Y)}

Dalam Uji Simultan (Uji F) nilai Regression pada kolom F diperoleh Fhitung 43,114 $>$ Ftabel $=3,09$ dengan taraf signifikansi (sig.) diperoleh nilai $0,000<0,05$ yang berarti bahwa hipotesis dalam penelitian ini $\mathrm{H}_{04}$ ditolak dan $\mathrm{H}_{\mathrm{a} 4}$ diterima.

Dengan demikian dapat disimpulkan bahwa hipotesis $\mathrm{H}_{4}$ "Penggunaan Media Sosial $\left(\mathrm{X}_{1}\right)$ dan Kreativitas $\left(\mathrm{X}_{2}\right)$ dan Pelatihan $\left(\mathrm{X}_{3}\right)$ berpengaruh terhadap Pengembangan Usaha (Y)" diterima. Besarnya pengaruh Penggunaan Media Sosial ( $\left.\mathrm{X}_{1}\right)$, Kreativitas $\left(\mathrm{X}_{2}\right)$ dan Pelatihan $\left(\mathrm{X}_{3}\right)$ terhadap Pengembangan Usaha $(\mathrm{Y})$ ditunjukkan oleh persamaan regresi, sebagai berikut: $\mathrm{Y}=34,000+0,0,206 \mathrm{X}_{1}+0,655 \mathrm{X}_{2 .}+0,124 \mathrm{X}_{3}$

Hal ini diperkuat dengan juga dengan penelitian yang dilakukan oleh Ni Ketut Arniti (2019), dengan judul Pengaruh Kompetensi Wirausaha, Kreativitas dan Penggunaan Media Sosial terhadap Perkembangan Usaha Kerajinan Batu Padas Banjar Silakarang, Gianyar, Vol.13 No.11 Juni 2019.Besarnya nilai thitung untuk variabel penggunaan media sosial sebesar 2,116 > ttabel1,697 dengan tingkat signifikansi 0,042 .

Berarti secara parsial penggunaan media sosial memiliki pengaruh yang nyata terhadap perkembangan usaha batu padas Banjar Silakarang, Singapadu, Kecamatan Sukawati besarnya nilai thitung untuk variabel kreativitas sebesar 2,962 > ttabel1,697 dengan tingkat signifikansi 0,006. Secara parsial kreativitas memiliki pengaruh yang nyata terhadap perkembangan usaha batu padas Banjar Silakarang, Singapadu, Kecamatan Sukawati. Penulis memberikan saran pada perajin batu pada Banjar Silakarang Singapadu Kecamatan Sukawati adalah Dinas terkait diharapkan dapat berperan aktif dalam melakukan monitoring dan evaluasi secara periodik, misalnya dilakukan setiap akhir bulan untuk mengetahui perkembangan batu padas pada khususnya dan pelaku-pelaku usaha lain pada umumnya, dan penggunaan media sosial perlu ditingkatkan lagi dalam promosi penjualan usaha batu padas Banjar 
Silakarang, Singapadu, Kecamatan Sukawati, agar usaha batu padas tersebut berkembangan menjadi usaha batu padas dengan skala yang lebih besar.

\section{PENUTUP}

\section{Simpulan}

Berdasarkan hasil dan pembahasan pada bab sebelumnya tentang pengaruh penggunaan media social, kreativitas dan pelatihan terhadap pengembangan usaha pada UMKM Coffee Shop Kota Bekasi dapat disimpulkan bahwa pada taraf nyata 5\%:

1) Berdasarkan Uji Parsial (Uji t), nilai thitung sebesar 2,207 $>t_{\text {tabel }}$ sebesar 1,984 dan nilai signifikansi sebesar $0,030<0,05$, maka dapat disimpulkan $\mathrm{H}_{\mathrm{o}}$ ditolak dan $\mathrm{H}_{\mathrm{a}}$ diterima, menjawab hipotesis ke-1 artinya "Penggunaan media sosial berpengaruh terhadap pengembangan usaha pada usaha coffee shop di Kota Bekasi.

2) Berdasarkan Uji Parsial (Uji t), nilai thitung sebesar 5,181 $>t_{\text {tabel }}$ sebesar 1,984 dan nilai signifikansi sebesar $0,000<0,05$, maka dapat disimpulkan $\mathrm{H}_{0}$ ditolak dan $\mathrm{H}_{\mathrm{a}}$ diterima, menjawab hipotesis ke-2 artinya "Kreativitas berpengaruh terhadap pengembangan usaha pada usaha coffee shop di Kota Bekasi

3) Berdasarkan Uji Parsial (Uji t) Nilai thitung sebesar $1.419<t_{\text {tabel }}$ sebesar 1,984 dan nilai signifikansi sebesar $0,159>0,05$ artinya dapat disimpulkan $\mathrm{H}_{0}$ diterima dan $\mathrm{H}_{\mathrm{a}}$ ditolak, menjawab hipotesis ke-3 artinya "Pelatihan tidak berpengaruh terhadap Pengembangan usaha pada usaha coffee shop di Kota Bekasi.

4) Berdasarkan Uji Simultan (Uji F), nilai $F_{\text {hitung }}=43,114>F_{\text {tabel }}=3,09$, dan nilai signifikansi $0,000<0,05$, yang berarti bahwa hipotesis dalam penelitian ini $\mathrm{H}_{0}$ ditolak dan $\mathrm{H}_{\mathrm{a}}$ diterima. Menjawab hipotesis ke-4, artinya "Penggunaan Media Sosial, Kreativitas dan Pelatihan terdapat pengaruh yang positif dan signifikan secara simultan terhadap Pengembangan Usaha pada usaha coffee shop di kota Bekasi.

Nilai Koefisien Determinasi sebesar 0,481 yang artinya bahwa kontribusi pengaruh adapun persamaan regresinya dengan rumus $Y=a+b_{1} X_{1}+b_{2} X_{2}+b_{3} X_{3}$ adalah $Y=$ $34,000+0,206 \mathrm{X}_{1}+0,655 \mathrm{X}_{2}+0,124 \mathrm{X}_{3}$ Dimana koefisien determinasi Penggunaan Media Sosial $\left(\mathrm{X}_{1}\right)$, Kreativitas $\left(\mathrm{X}_{2}\right)$ dan Pelatihan $\left(\mathrm{X}_{3}\right)$ terhadap Pengembangan Usaha $(\mathrm{Y})$ UMKM Coffee Shop adalah sebesar 48,1\%, sedangkan sisanya sebesar 51,9\% dipengaruhi oleh faktor lain yang tidak dibahas dalam penelitian ini. 


\section{Saran}

Berdasarkan hasil pembahasan serta beberapa kesimpulan pada penelitian ini, adapun saran-saran yang dapat diberikan penulis adalah sebagai berikut:

1. Sebaiknya pemilik usaha dalam menjalankan usahannya untuk tetap mempertahankan dan meningkatkan pelaksanaan strategi pemasaran dengan menggunakan berbagai macam media sosial untuk memperkenalkan produk dan memasarkan produk kepada konsumen, serta agar terus dapat bersaing dengan kompetitor.

2. Sebaiknya pemilik usaha dalam menjalankan usahanya untuk tetap mempertahankan dan meningkatkan, sebuah kreativitas agar memiliki ciri khas tersendiri yang dapat membedakan produk sendiri dan kompetitor lain.

\section{Rekomendasi Peneliti selanjutnya.}

Dengan hasil penelitian ini diharapkan dapat memberikan masukan bagi penelitianpenelitian selanjutnya demi mengembangkan ilmu pengetahuan secara umum dan khususnya dalam bidang UMKM. 


\section{DAFTAR PUSTAKA}

Agustina, T. S. (2015). Kewirausahaan teori dan penerapan pada Wirausaha dan UKM di Indonesia. Mitra Wacana Media.

Arini T. Soemohadiwidjojo. (2018). SOP dan KPI untuk UMKM \& STARTUP. Raih Asa Sukses.

Arniti, N. K. (2019). Pengaruh Kompetensi Wirausaha, Kreativitas dan Penggunaan Media Sosial Terhadap Perkembangan Usaha Kerajinan Batu Pada Banjar Silakarang Gianyar. Media Bina Ilmiah, 13 (11)

Budiarto, R. (2019). Pengembangan UMKM Antara Konseptual dan Pengalaman Praktis. Gadjah Mada University Press.

Cahyanti, M. M., \& Anjaningrum, W. D. (2017). Faktor-Faktor Yang Mempengaruhi Perkembangan Usaha Kecil Sektor Industri Pengolahan Di Kota Malang. Jurnal Ilmiah Bisnis Dan Ekonomi Asia, 11(2).

David Wijaya. (2018). Akuntansi UMKM. Gava Media.

Dharmawati, M. (2019). Kewirausahaan. Fajar Interpratama Mandiri.

ES, D. P., Juhaeriah, S., \& Sudiarditha, I. K. R. (2017). Pengaruh Pelatih dan Kreativitas terhadap Pengembangan Usaha pada Usaha Kecil dan Menengah di Perkampungan Industri Kecil Pulogadung Jakarta Timur. Jurnal Ilmiah Econosains, 15(1), 76-90.

Hanoatubun, S. (2020). Dampak Covid-19 terhadap Prekonomian Indonesia. EduPsyCouns: Journal of Education, Psychology and Counseling, 2(1), 146-153.

Hendrawan, A., Kuswantoro, F., \& Sucahyawati, H. (2019). Dimensi Kreativitas dan Pengembangan Usaha Mikro Kecil dan Menengah (UMKM). Jurnal HUMMANSI (Humaniora, Manajemen, Akuntansi), 2(1).

Data Penjualan Cofee.2020. https://databoks.katadata.co.id/, diakses tanggal 18 Agustus $\underline{2021}$

Trade Statistik. 2020. ttps://brewfest.com. diakses tanggal 17 Agustus 2021

Data UMKM Yang Terdampak Covid-19. 2021. https://www.bps.go.id/,(2021). diakses tanggal 20 Juli 2021

Satriyo, Eddy. 2020. Dampak Covid-19. http://www.depkop.go.id/. diakses tanggal 12 Agustus 2021 
Imam Ghozali. (2013). Aplikasi Analisis Multivariate dengan Program IBM SPSS 21. Universitas Diponegoro.

Jaya, I. M. L. M. (2020). Metode Penelitian Kuantitatif dan Kualitatif. Quadrant

Joko Rizkie Widokarti dan Donni Juni Prinsa. (2019). Konsumen, Pemasaran, Komunikasi Kontemporer. Pustaka Setia.

Manap, A. (2018). Manajemen Kewirausahaan. Mitra Wacana Media.

Nasrullah, R. (2017). Media Sosial. Simbiosa Rekatama Media.

Pradhana, I. P. D., \& Yella, M. D. M. (2019). Pengaruh Karakteristik Kewirausahaan, Kreativitas dan Inovasi terhadap Perkembangan Usaha Pedagang di Pasar Seni Guwang Sukawati. Media Bina Ilmiah, 14(1).

Priansa, D. J. (2017). Komunitas Pemasaran Terpadu. Pustaka Setia.

Purwidiantoro, M. H., SW, D. F. K., \& Hadi, W. (2016). Pengaruh penggunaan media sosial terhadap pengembangan usaha kecil menengah (UKM). Eka Cida, 1(1).

Soleha, S., Pranoto, Y. S., \& Evahelda, E. (n.d.). Valuasi Ekonomi Objek Wisata Hutan Mangrove Munjang di Desa Kurau Barat Kabupaten Bangka Tengah. SOCA: Jurnal Sosial Ekonomi Pertanian, 14(1).

Solis. (2010). Engage

Sugiyono. (2017). Metode Penelitian Kuantitatif, Kualitatif, dan R\&D. CV alfabeta.

Sujarweni, V. W. (2018). Metodologi Penelitian. Pustaka Baru Press.

Syofian Siregar. (2017). Metode Penelitian Kuantitatif dilengkapi dengan perbandingan perhitungan manual \& SPSS. Kencana.

Tambunan, T. T. H. (2017). Usaha Mikro Kecil dan Menengah. Ghalia Indonesia.

Tri Siwi Agustina. (2015). Kewirausahaan Teori dan Penerapan pada Wirausaha dan UKM di Indonesia. Mitra Wacana Media.

UU No. 20 Tahun 2008. (2008).

Weinberger, E., Wach, D., Stephan, U., \& Wegge, J. (2018). Having a creative day: Understanding entrepreneurs' daily idea generation through a recovery lens. Journal of Business Venturing, 33(1), 1-19.

Widodo. (2019). Metodologi Penelitian Populer \& Praktis. Kharisma Putra Utama Offset. 